
РАССТРОЙСТВ

(c) Y. Chahirou, A. Mesfioui, A. Ouichou, A. Hessni

Университет имени Ибн Тофэйля, г. Кенитра, Марокко

Текущие исследования показывают, что метаболические и поведенческие расстройства представляют собой существенную медицинскую проблему. Возникают вопросы о молекулярных причинах метаболических и поведенческих расстройств. В этом обзоре рассматривается взаимосвязь липидного обмена и потребления фруктозы, сопровождающаяся увеличением массы тела, а также сопутствующими расстройствами: гипертензией, инсулинорезистентностью, оксидативным стрессом и депрессией. Жировая ткань рассматривается как гормонпродуцирующая ткань с высокой секреторной активностью (метаболической и провоспалительной). Адипокины (гормоны жировой ткани) отвечают за регуляцию некоторых физиологических функций. В этом обзоре предпринята попытка разобраться как липогенез, приводящий к дислипидемии, воздействует на инсулинорезистентность, гипертензию, оксидативный стресс, депрессию, а также определить взаимосвязь между этими нарушениями.

КЛЮЧЕВЫЕ СЛОВА: депрессия, фруктоза, гипертензия, инсулинорезистентность, липогенез, липолиз, окислительный стресс.

\title{
ADIPOKINES: MECHANISMS OF METABOLIC AND BEHAVIORAL DISORDERS
}

(c) Yassine Chahirou, Abdelhalim Mesfioui, Ali Ouichou, Aboubaker Hessni

Ibn Tofail University, Kenitra, Morocco

Current studies show that metabolic and behavioral disorders represent severe health problems. Several questions arise about the molecular relationship of metabolic and behavioral disorders. This review will discuss the relationship of lipid metabolism and fructose consumption accompanied by an increase in weight as well as associated disorders: hypertension, insulin-resistance, oxidative stress and depression. Adipose tissue is considered as an endocrine tissue with intense secretory activities (metabolic and inflammatory). These adipokines are responsible for an alteration of several physiological functions. In this review we will try to understand how lipogenesis that causes dyslipidemia can influence insulin resistance, hypertension, oxidative stress, depression and the relationship between these various disorders.

KEYWORDS: depression, fructose, hypertension, insulin resistance, lipogenesis, lipolysis, oxidative stress.

\section{ВВЕДЕНИЕ}

Метаболические и дегенеративные расстройства, ассоциированные с дисбалансом питания (сердечно-сосудистая патология, диабет, ожирение, депрессия и др.) это самые распространенные заболевания в мире [1]. Такие заболевания всесторонне изучаются исследователями: пища, условия окружающей среды, генетика, фенотип (эпигенетика). Несмотря на проводимые исследования в данной области, частота ожирения и нарушений обмена веществ резко возрастает вслед за изменениями, происходящими в образе жизни и питании, особенно при диете с высоким содержанием фруктозы и жиров [2]. Эта эпидемия сопровождается когнитивными и аффективными расстройствами, оксидативным стрессом и повреждением ключевых ферментов в физиологическом гомеостазе.

\section{ВЫСОКОКАЛОРИЙНАЯ ДИЕТА И ОЖИРЕНИЕ}

Метаболизм фруктозы и липидов

Фруктоза - это простой моносахарид с высокой подслащивающей способностью, сравнимой с глюкозой и сахарозой. Потребление этого моносахари- да значительно возросло за последнее десятилетие. Абсорбция фруктозы происходит при помощи специфических переносчиков GLUT5 (глюкозный транспортер тип 5) на апикальной мембране щеточной каемки энтероцитов и GLUT2 (глюкозный транспортер тип 2) в воротной вене [3]. Фруктоза практически полностью метаболизируется в печени с помощью фермента фруктокиназы [4]. Данный процесс протекает независимо от секреции инсулина [5]. В печени фруктоза быстро превращается в фосфотриозу (глицеральдегид-3-фосфат) независимо от наличия инсулина. Избыток фосфотриозы образует ацетил-КОА, который, в свою очередь, трансформируется в свободные жирные кислоты, этерифицирующиеся в триглицериды (ТГ) в клетках печени в процессе липогенеза [6, 7]. Данный процесс вызывает повышение уровня триглицеридов и ЛПОНП (липопротеидов низкой плотности) в плазме с развитием жирового гепатоза, нарушение толерантности к глюкозе, инсулинорезистентность и развитие гипертонии $[8,9]$.

Высокое потребление жиров повышает плазменную концентрацию хиломикронов, содержащих неэтерифицированные жирные кислоты, в процессе катаболизма которых в мышцах вырабатывается аденозинтрифосфат 


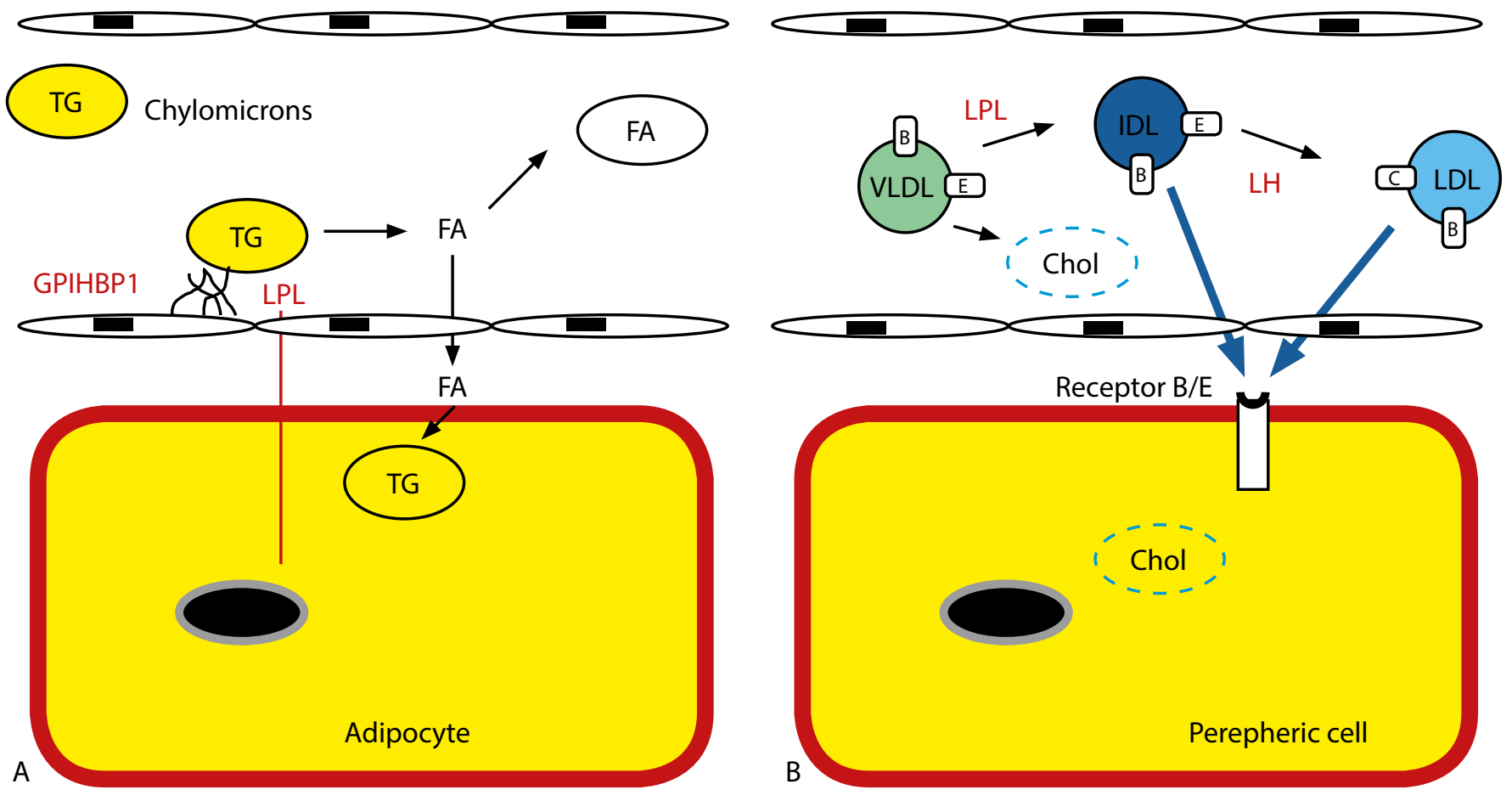

Рис. 1. Захват жирных кислот из хиломикронов и холестерина, полученных из липопротеинов очень низкой плотности (ЛПОНП/ VLDL). (A) Схематическое изображение липогенеза из хиломикронов. Проникновение жирных кислот (ЖК/FA) в адипоциты обеспечивается липопротеиномсвязывающим белком 1 с высокой плотностью связывания с гликофосфатидилинозитолом (GPIHBP1), который является связывающей молекулой, и липопротеинлипазой (ЛПЛ/LPL), которая гидролизует триглицериды до жирных кислот (ЖK/FA).

(B) Схематическое изображение липогенеза из эндогенных липидов: под действием липопротеинлипазы (Лпл/LPL) липопротеины очень низкой плотности (ЛПОНП/VLDL) трансформируются в липопротеины промежуточной плотности (ЛПП/IDL), которые, в свою очередь, трансформируются в липопротеины низкой плотности (ЛПНП/LDL) под действием печеночной липазы (ПЛ/LH), высвобождая холестерин; ЛПП (липопротеины промежуточной плотности) затем захватываются рецептором (B/E): В (аполипротеин типа В), Е (аполипротеин типа Е). Аполипопротеины представляют собой поверхностные белки ЛПОНП. За счет них производится перенос ЛПОНП в плазме и распознавание клетками.

(АТФ), в адипоцитах - ТГ [10], в печени - ЛПОНП и кетоны, что на фоне инсулинорезистентности часто приводит к развитию метаболического ацидоза [9].

На фоне сбалансированной диеты клеточный метаболизм контролирует соотношение АТФ/АМФ (аденозинмонофосфат) и НАДФН ${ }_{2}+$ (никотинамидадениндинуклеотидфосфат)/НАД+, таким образом контролируя обмен ферментов. Снижение этого соотношения вызывает активацию АМФК (протеинкиназа, активируемая АМФ) и сиртуинов: ключевых ферментов в регуляции некоторых физиологических процессов [11]. Основная роль АМФК заключается в фосфорилировании и ингибировании ГМГ-КоА-редуктазы (гидроксиметилглутарил-КоА-редуктазы) и ацетил-КоА-карбоксилазы, таким образом снижая уровень триглицеридов и интенсивность биосинтеза холестерина [12]. Несколько недавних исследований показали, что существует взаимосвязь между АМФК и сиртуинами, механизмом действия которых является дезацетилирование [13] Эти ферменты надолго связываются с несколькими факторами транскрипции (foxo3, PGC-1 a, PPAR-a), активируя их. Это влечет за собой увеличение скорости таких процессов, как катаболизм, окисление глюкозы, образование митохондрий, которые часто нарушаются в ходе старения организма. Данные процессы нарушаются при высококалорийной диете, вызывая увеличение соотношения АТФ/АМФ и НАДФН ${ }_{2}+/$ НАД+.

\section{Накопление триглицеридов}

ТГ синтезируются из жирных кислот и глицерол-3-фосфата. ТГ переносятся в форме ЛПОНП, если они поступили из печени, или хиломикронов, если они поступили в организм с пищей. Покидая печень, ЛПОНП переносят эндогенные триглицериды и холестерин, превращаясь в липопротеины промежуточной плотности (ЛПП) под воздействием ЛПЛ (липопротеинлипазы) и в липопротеины низкой плотности (ЛПНП) под воздействием печеночных липаз. ЛПНП и ЛПП связываются со специфическими рецепторами в периферии.

Гидролиз ТГ, транспортирующихся в форме липопротеинов, осуществляется с помощью ЛПЛ, образуя глицерол и жирные кислоты. Несколько исследований показали, что ЛПЛ синтезируется на ранних стадиях дифференцировки адипоцитов, но активируется только в зрелых адипоцитах [14]. ЛПЛ связывается с поверхностью эндотелиальных клеток капилляров путем взаимодействия с гликозаминогликанами, а также с GPIHBP1 (гликофосфатидилинозитол якорный липопротеин высокой плотности, связывающий белок 1), который является связывающей молекулой [15].

В процессе гидролиза ТГ с помощью ЛПЛ высвобождаются жирные кислоты и глицерин, которые проникают в адипоциты, в то время как их избыток является основной характеристикой ожирения (рис. 1).

\section{Контроль липолиза}

Запасы жировой ткани (ЖТ/АТ) в основном мобилизуются во время голодания, физических нагрузок и различных стрессовых ситуаций (например, психологический стресс). ТГ жировой ткани гидролизуются с высвобождением глицерина и неэтерифицированных жирных кислот (НЭЖК/NEFA), которые поступают в плазму.

НЭЖК, связываясь с альбумином плазмы, транспортируются к органам-мишеням (в частности, в скелетные 


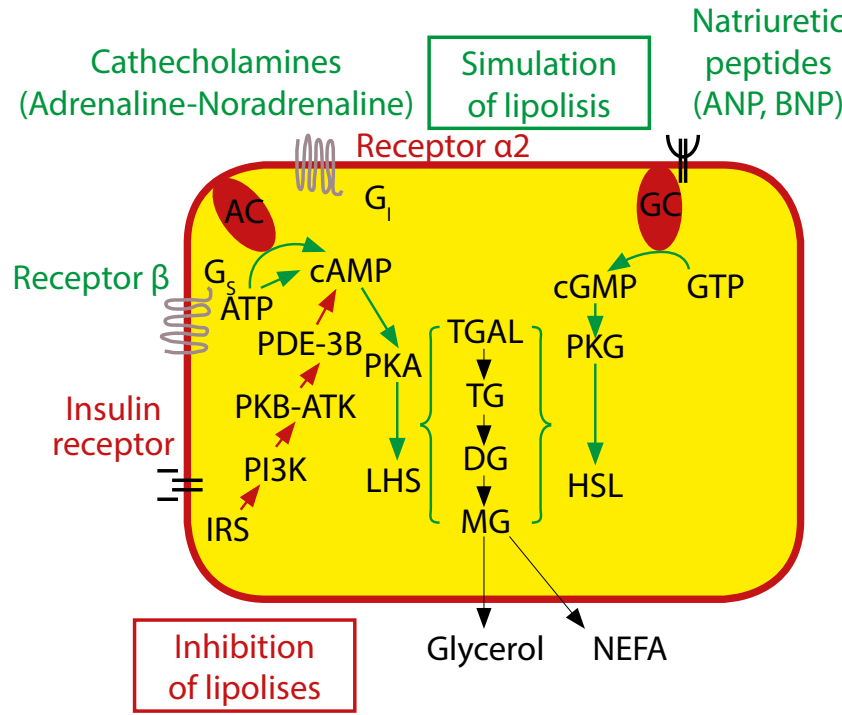

Рис. 2. Контроль липолиза и липогенеза натрийуретическими пептидами, катехоламинами и инсулином: натрийуретические пептиды и катехоламины стимулируют липолиз, активируя гормон-чувствительную липазу (ГЧЛ/HSL), в то время как инсулин является мощным ингибитором липолиза, уменьшая активацию ГЧЛ.

НЭЖK (NEFA) - неэтерифицированные жирные кислоты; ПНП (ANP) предсердный натрийуретический пептид; ТГЛА (TGLA) - триглицеридная липаза адипоцита; ВНП (BNP) - натрийуретический пептид В-типа; ДГ (DG) - диглицериды; ГЦ (GC) - гуанилилциклаза; Ги-ГТФ - ингибиторы ГТФ-связывающего белка; Гс-ГТФ - стимуляторы ГТФ-связывающего белка; СРИ-1 (IRS-1) - субстрат рецептора инсулина-1; ГЧЛ (HSL) чувствительная к гормонам липаза; МГ (MG) - моноглицериды; ФИЗК(PI3-K) - фосфатидилинозитол-3-киназа; ПКВ/Akt (PKB/Akt) - белок АКТ ранее известный как ПКВ - протеинкиназа В; ТГ (TG) - триглицериды.

мышцы, сердце, печень). Данный процесс является объектом мощного нейрогормонального контроля [16].

Липидная капля внутри адипоцита окружена различными белками [10], наиболее важный среди них - перилипин, который предотвращает липолиз в базальной среде, блокируя воздействие ЛПЛ на липидную каплю.

Три типа липаз участвуют в контроле гидролиза ТГ. Самой первой была обнаружена гормон-чувствительная липаза (ГЧЛ/HSL). Вторая липаза - адипоцитарная триглицеридная липаза (АTГЛ/ATGL) недавно была обнаружена тремя независимыми группами ученых. Данная липаза обладает исключительной активностью в гидролизе ТГ в ЖТ. Активность этих двух ферментов контролируется в определенном согласованном порядке. Третья липаза (липаза моноглицеридов - ЛМГ/LMG) широко распространенная в адипоцитах, гормонами не регулируется [17].

Активация липидов регулируется синергидными и взаимодополняющими механизмами. Она стимулируется катехоламинами (адреналином и норадреналином) и натрийуретическими пептидами и ингибируется инсулином [18]. Стимуляция бета-адренергических рецепторов активирует Гc(Gs)-белки (а-субъединицы высвобождают ГДФ и связывают ГТФ), диссоциация трех субъединиц может затем стимулировать различные клеточные взаимодействия, цАМФ, продуцируемый в ходе активации аденилилциклазы (АЦ), активирует протеинкиназу А (ПКА) (рис. 2), которая стимулирует фосфорилирование перилипинов, ГЧЛ и других белков-мишеней адипоцита. Натрийуретические пептиды стимулируют активность гуанилилциклазы (ГЦ) - рецептора натрийуретических пептидов, индуцируя увеличение уровней
цГМф, активируя фосфорилирование протеинкиназы G (ПКG) и активируя ГЧЛ. Эта молекула гидролизует трии диглицериды. Моноглицериды гидролизуются с помощью липазы моноглицеридов (ЛМГ).

Липолитическая активность адипоцитов человека находится под постоянным контролем пролиполитиков (бета-адренергических, натрийуретических пептидов) и антилиполитиков (инсулин, аденозин, простагландины, NPY (нейропептид Y) и альфа-адренергические пути) [19].

Полный гидролиз триглицеридов высвобождает неэтерифицированные жирные кислоты и глицерин. ГЧЛ способствует высвобождению неэтерифицированных ЖК путем простой диффузии, в то время как высвобождение глицерина стимулируется АП-7 (аквапорин-7). Инсулин через его рецепторы активирует сигнальный путь (IRS-1, PI3-K, PKB/Akt, который играет ключевую роль в мультиклеточных процессах, таких как метаболизм глюкозы и липидов), а также путь PDE-3B (фосфодиэстераза-3В), вызывающий распад цАМФ. Инсулин обладает антилиполитическим эффектом посредством контроля зависимого от цАМФ пути.

\section{Жировая ткань и воспаление}

ЖТ, долгое время считающаяся резервной, оказалась полноценным эндокринным органом. ЖК, а также клетки сосудистой стромы ЖТ участвуют в высвобождении молекул, обладающих аутокринными и паракринными эффектами [20]. Белая ЖТ представляет собой эндокринный орган с мощной способностью выделять большое количество белковых факторов - адипокинов [21].

Таким образом, адипоциты выделяют лептин и адипонектин, гормоны, участвующие в контроле гомеостаза энергии, а также воспалительные молекулы, такие как хемокины, белки острой фазы, включая С-реактивный белок, а также воспалительные цитокины, TNFa и IL-6. Было показано, что ЖТ вырабатывает большое количество белков, связанных с воспалением, но гены, кодирующие эти белки, преимущественно локализованы в стромально-сосудистой части, состоящей из клеток различных штаммов, включая преадипоциты, эндотелиальные клетки, а также макрофаги [22]. Накопление макрофагов в ЖТ зависит от активности продуцирования воспалительных цитокинов, что наблюдается при ожирении [22]. Следовательно, ЖТ является причиной развития ожирения за счет прогрессирующего воспаления и инфильтрации макрофагами [23]. На ранних стадиях ожирения адипоциты выделяют небольшие количества TNFa, которые стимулируют продуцирование моноцитарного хемоаттрактантного белка-1 (МСР-1) преадипоцитами [24]. Подобным образом эндотелиальные клетки способны секретировать МСР-1 в ответ на цитокины, что позволяет привлекать макрофаги в ЖТ. Более того, повышенная секреция лептина адипоцитами может также способствовать накоплению макрофагов, облегчая их проникновение в ЖТ посредством стимуляции ангиогенеза [25].

Высококалорийная диета и расстройства метаболизма

Повышенное потребление жиров и углеводов запускает липогенез за счет активации ацетил-КоА-карбоксилазы, которая превращает ацетил-КоА в малонил-КоА, из которого затем образуются жирные кислоты. Такое со- 


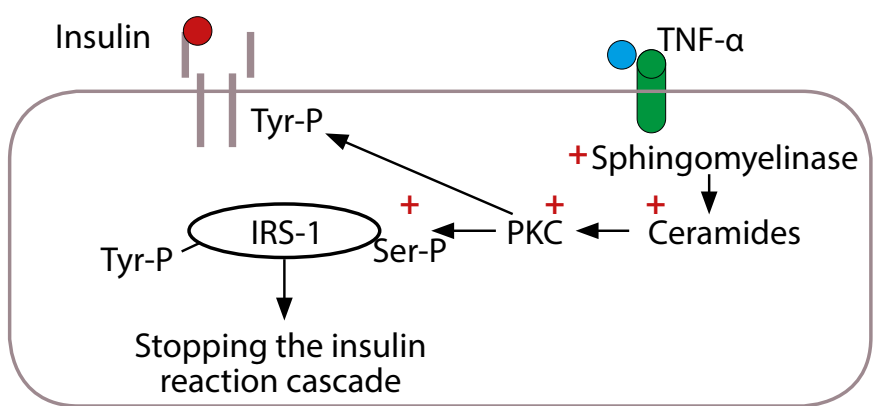

Рис. 3. Развитие инсулинорезистентности за счет адипокинов. Вслед за накоплением триглицеридов, адипоциты и стромально-сосудистые клетки начинают продуцировать ФНО-а (TNF-a) (фактор некроза опухолей альфа), это активирует адипокиновую сфингомиелиназу, ответственную за активацию внутриклеточных белков, участвующих в снижении активации IRS (субстрат рецептора инсулина).

стояние сопровождается развитием стеатоза печени, что в сочетании с продукцией ФНО-а (TNF-a), по-видимому, становится главной причиной инсулинорезистентности, которая вторична по отношению к ожирению. При сниженной активности инсулина увеличивается экспрессия белка, связывающего тирозин (РТВ), ингибирующего связывание IRS с инсулиновым рецептором [26].

Воспаление, вызванное привлеченными макрофагами, также увеличивает фосфорилирование IRS1 на сериновых остатках, тем самым блокируя действие инсулина [27]. TNF-a, экспрессия которого увеличивается в ЖТ у людей или животных с ожирением и инсулинорезистентностью, действует на рецептор TNFR1, активируя сфингомиелиназу, которая усиливает выработку РКС. Это соединение блокирует активацию IRS1, индуцируя фосфорилирование белка до сериновых остатков в эндотелиальных клетках и гепатоцитах (рис. 3) [28].

Гипертензия является основным фактором риска для большинства сердечно-сосудистых заболеваний. Недавно лептин был идентифицирован как гормон, который повышает тонус симпатической нервной системы, резистентность к лептину часто сопровождается гиперсимпатикотонией и увеличением активности системы ренин-ангиотензин-альдостерон [1]. Адреналин, связывающийся с альфа-1-рецепторами, активирует PLC, который усиливает выброс IP3 и РКС, что увеличивает кровяное давление, тот же эффект наблюдается, когда ангиотензин присоединяется к его АТ1-рецептору, связанному с альфа-1-субъединицей рецептора Gaq на плазматической мембране клеток гладкой мускулатуры [1]. Для пациентов с ожирением гипертрофия левого желудочка является характерной и часто ассоциируется с застойной сердечной недостаточностью [29]. Висцеральная жировая ткань ассоциируется со значительным увеличением ТГ (TGs) и пониженным уровнем ЛПВП, а также с увеличением ApoB и LDL [30]. В то время как низкоплотные частицы ЛПНП циркулируют дольше, легче проникают в мембрану эндотелиальной стенки и прилипают к молекулам адгезии, вызывая атеросклероз [31].

При таком расстройстве метаболизма изменяется экспрессия других ферментов, особенно АМФК (АМРК) и сиртуинов, увеличение образования АТФ и НАДФН+ уменьшает активность этих ферментов, что обусловлено низкой активностью PGC-1a, FOXO, следствием которой являются дисрегуляция гликемии и митохондриальная дисфункция с увеличением mTOR (мишени рапамицина
Intermembrance space

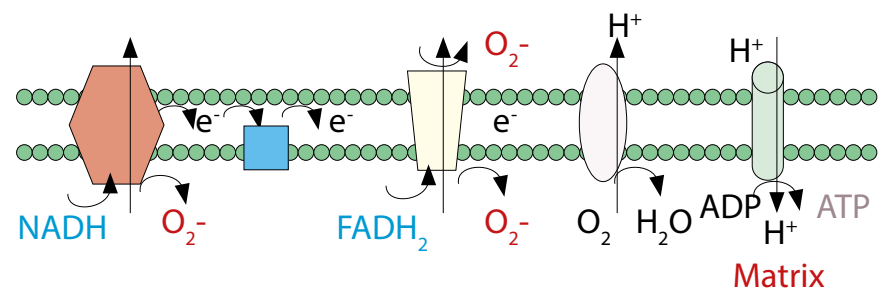

Рис. 4. Образование свободных радикалов в процессе клеточного дыхания: схематическое изображение образования свободных радикалов, избыточное производство NADH (никотинамидадениндинуклеотида) и $\mathrm{FADH} 2$ (флавинадениндинуклеотида) приводит к дисфункции комплексов I и III, что сопровождается чрезмерным высвобождением $\mathrm{O}^{2}$ - (анион супероксида).

млекопитающих), замедляющие реакции каскада инсулина [32].

Оксидативный стресс является одним из последствий гиперкалорийной диеты. В процессе клеточного катаболизма образуются переносчики, обогащенные протонной энергией: NADH'H+ и FADH2. Эти молекулы подвергаются окислительному фосфорилированию на внутренней мембране митохондрий с целью получения АТФ. Эти реакции сопровождаются образованием небольшого количества супероксидного аниона $\mathrm{O}^{2}$ - [33].

Высококалорийная диета или накопление ацетил-КоА нарушают комплексы I и III дыхательной цепи посредством реакций, которые не очень хорошо изучены, ускоряя образование супероксидных анионов и увеличивая их количество в этих комплексах [34].

Образование $\mathrm{O}^{2}$ - приводит к избыточному образованию AФК (ROS) (активных форм кислорода), наиболее известной из которых является пероксинитрит ONOO, который разрушает плазматическую мембрану путем перекисного окисления липидов, взаимодействуя с фосфолипидами жирных кислот [35]. Образование перекиси водорода $\mathrm{H}_{2} \mathrm{O}_{2}$ изменяет клеточный компартмент: ДНК и функцию митохондрий посредством реакции Фентона [33]: $\mathrm{H}_{2} \mathrm{O}_{2}+\mathrm{Fe}^{2+}==>\mathrm{OH}+\mathrm{OH}^{-}+\mathrm{Fe}^{3+}$. $\mathrm{ROS}$ являются основной причиной старения в соответствии с теорией свободных радикалов. Они нарушают обмен веществ и вызывают некоторые нейронные заболевания, такие как болезнь Паркинсона и болезнь Альцгеймера [35].

\section{ДИЕТА С ВЫСОКИМ СОДЕРЖАНИЕМ КАЛОРИЙ И ПОВЕДЕНЧЕСКИЕ РАССТРОЙСТВА}

\section{Адипокины, моноамины и поведенческие}

расстройства

Исследования показали, что у людей с депрессией отмечены более высокая продукция провоспалительных цитокинов (TNF-a, IFN- $\gamma$, IL-6) и более низкая продукция противовоспалительных цитокинов (IL-4, IL-10) [36]. Аналогичным образом было показано, что лечение иммунотерапией IFN-a у пациентов с раком приводит к поведенческим изменениям, таким как тревога и депрессия [37]. Также вероятно, что гипоталамо-гипофизарная ось (HPA) может связывать ожирение, тревогу и депрессию, поскольку была продемонстрирована дефектная отрицательная обратная связь оси НРА [38]. Исследования в этой области показывают, что хроническая активация гипоталамо-гипофизарной оси вызвана резистентностью к глюкокортикоидам, возникающей в результате на- 

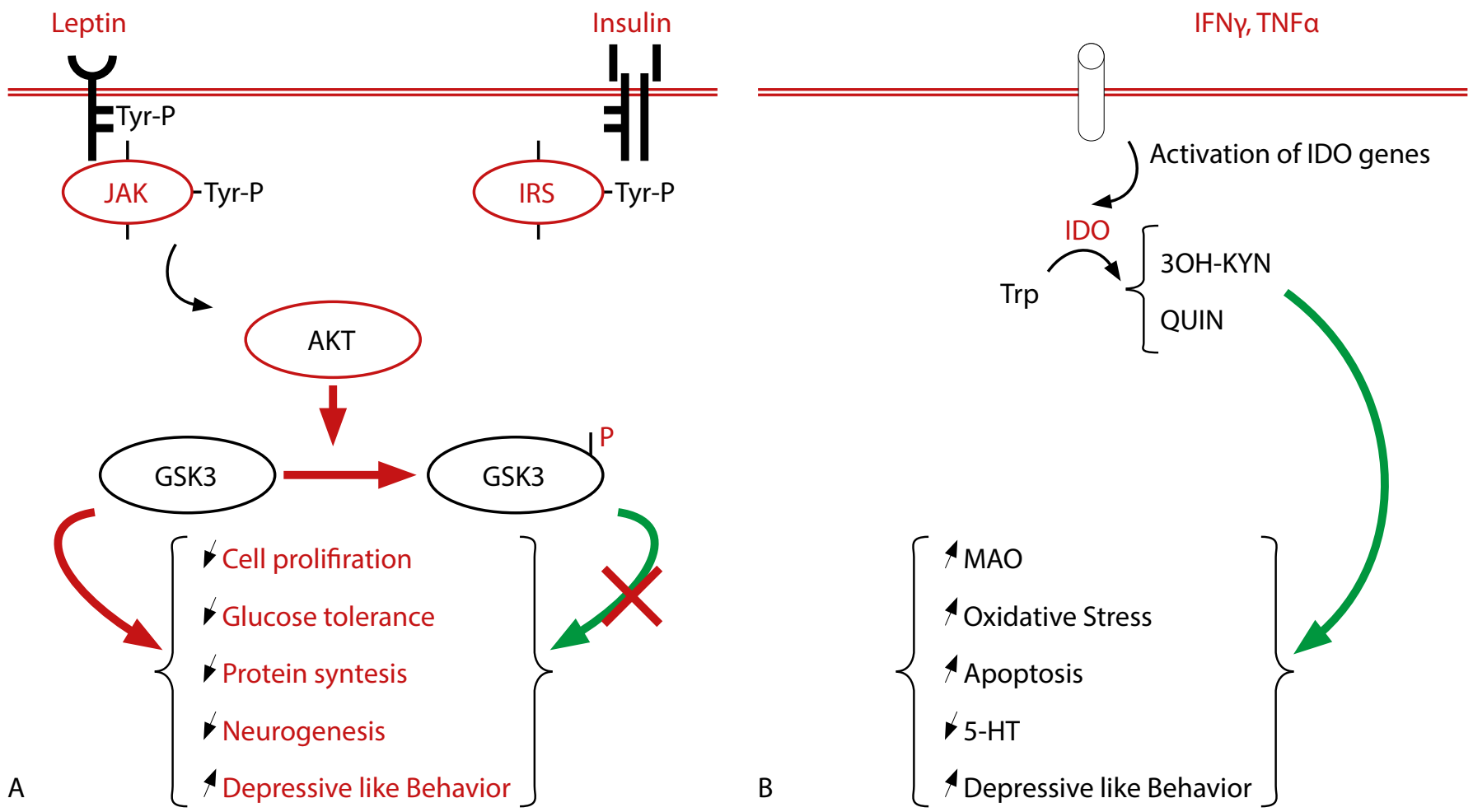

Рис. 5. Роль адипокинов в развитии поведенческих расстройств: (А) схематическое изображение влияния инсулина и лептина на поведение. (B) Схематическое изображение влияния цитокинов на поведение.

личия нефункционального рецептора в гипофизе, также как хроническое воздействие глюкокортикоидов на гиппокамп и ПФК (префронтальную кору) вызывает атрофию этих структур мозга, что приводит к депрессии [39].

В случае ожирения, которое характеризуется хроническим воспалением, продуцируемые цитокины способствуют симпатической активности, которая, в свою очередь, способствует активации иммунной системы и высвобождению воспалительных цитокинов [40]. Эти молекулы нарушают моноаминергические и нейротрофические сигналы, приводя к изменениям в нейротрансмиссии серотонина [5-HT), норадреналина (NE) и допамина (DA), а также снижают чувствительность центральных кортикостероидных рецепторов, что приводит к снижению обратной связи [40].

Молекулярные механизмы, приводящие к атрофии нейронов, многочисленны: глутамат и серотонин могут влиять на ростовые факторы BDNF, EGF и FGF, которые увеличивают образование дендритных шипов [41]. Цитокины влияют на эти нейротрофические факторы с помощью механизмов, которые еще предстоит изучить [38]. Кроме того, концентрации глюкокортикоидов, значительно возрастающие у людей с ожирением, способны снижать уровни триптофана, ингибируя синтез 5-HT [42-43].

Адипокины, нейровоспаление и поведенческие расстройства

Белок IDO (индоламиндиоксигеназа) был обнаружен методом иммуногистохимии в гиппокампе у пациентов, которые получали инъекции цитокинов, таких как TNF-a и IFN-ү, или у пациентов с болезнью Альцгеймера [44]. Подавляющее большинство исследований механизмов активации IDO показывают, что IFN-ү как цитокин в основном отвечает за индукцию данного белка [45]. Однако последние данные свидетельствуют о вовлечении в этот процесс других воспалительных цитокинов, секретируемых жировой тканью и макрофагами.

Было отмечено, что активированный IDO, вероятно, способствует (через продукцию нейротоксических веществ, включая хинолиновую кислоту (QUIN)) гибели клеток при некоторых патологиях. Депрессия также может быть вызвана морфологическими и функциональными нарушениями мозга, которые могут возникнуть в результате активации IDO в результате воспаления [46]. Активированный IDO инициирует кинурениновый путь, который обладает нейротоксическим эффектом, особенно QUIN и 3-гидроксикинуренин (3ОH-KYN), который тоже оказывает нейротоксическое действие, индуцируя окислительный стресс и смерть путем апоптоза (рис. 5В). Кроме того, 3ОH-КYN увеличивает активность MAOs (моноаминоксидазы) и сам может участвовать в развитии расстройств настроения путем уменьшения количества 5-HT. Таким образом, QUIN и 3ОН-KYN действуют через плохо изученные механизмы, вызывая повреждение нейронов [47].

Что касается ожирения, то некоторые предварительные данные исследований указывают на наличие защитных эффектов генетической делеции IDO на набор веса в результате высококалорийной диеты и на развитие стеатоза печени у грызунов [48]. В клинической практике применение селективных ингибиторов IDO и родственных ферментов для лечения ожирения и нарушений обмена веществ не исследовалось, однако недавно полученные данные свидетельствуют о том, что мультимодальные методы лечения, такие как средиземноморская диета, основанная на высоком потреблении оливкового масла холодного отжима, фруктов и злаков [49], и физические упражнения [50] могут повлиять на метаболизм триптофана путем повышения в плазме уровня TRY и снижения уровней вредных продуктов катаболизма триптофана, особенно KYN. 
Воспалительные цитокины активируют фермент гуанозинтрифосфатциклогидролазу-1 (GTP-CH1), являющийся лимитным для синтеза неоптерина. Эта активация индуцирует образование неоптерина за счет тетрагидробиоптерина (BН4), кофактора тирозингидроксилазы, фермента, который необходим для синтеза катехоламинов, включая допамин. Снижение доступности BН4 приводит к снижению синтеза дофамина. Активация GTPCH1 цитокинами, косвенно измеряемая увеличением производства неоптерина, таким образом, может повлиять на производство допамина, который участвует в регуляции настроения [51]. В соответствии с этими данными отмечены пониженные уровни ВН4 и увеличенные концентрации неоптерина в крови у пациентов с депрессивным расстройством. Важно отметить, что у пожилых людей хроническое воспаление низкой активности сопровождается активацией IDO и GTP-CH1, что коррелирует с нейропсихиатрическими изменениями [52]. Кроме того, у пациентов с ожирением регистрировались высокие уровни неоптерина, из чего можно заключить, что активация GTP-CH1 цитокинами в контексте ожирения и возникающие в результате изменения дофаминергической нейротрансмиссии могут способствовать развитию нейропсихиатрических симптомов, связанных с ожирением.

\section{Инсулинорезистентность и поведенческие}

\section{расстройства}

Другая теория состоит в том, что ключевая роль в регуляции клеточного энергетического метаболизма может принадлежать гликогенсинтетазе киназе 3 (GSK-3). Как описано ранее, GSK-3 изначально изучался из-за его роли в фосфорилировании гликогенсинтетазы, действуя как важнейший регулятор эффектов инсулина на инсулин/РIЗкиназный/Akt-путь. Инактивация GSK-3 приводит к синтезу гликогена, активации рецептора инсулина путем снижения фосфорилирования IRS-1 и снижения фосфорилирования и активации GSK [53].

Нарушение метаболического профиля также связано с депрессией. Инсулинорезистентность повышает активность GSK-3, что неблагоприятно влияет на регуляцию клеточных функций на периферии и в гиппокампе [17]. Это часто приводит к биполярному расстройству, шизофрении и депрессии через $\beta$-катенин, который необходим для нейрогенеза и синаптогенеза [12], снижение экспрессии белка РКВ/АКТ часто наблюдается при резистентности к лептину и резистентности к инсулину (рис. 5A).

Существует другая молекула, которая играет очень важную роль на периферии и на центральном уровне, чья концентрация отрицательно коррелирует с резистентностью к инсулину. Адипонектин является наиболее значимым представителем противовоспалительных адипокинов [31]. Было показано, что эта молекула ингибирует передачу NFkB в эндотелиальных клетках, уменьшая воспаление, вызванное адипокинами [26]. Адипонектин действует через два рецепторных подтипа AdipoR1 и AdipoR2 и опосредует их действие преимущественно через аденозинмонофосфат-активированную протеинкиназу (AMPK) [53]. Интересно, что уровни адипонектина в плазме снижаются при ожирении [36]. В целом этот адипокин представляется перспективным кандидатом для лечения/снижения выраженности первичного хронического воспаления и вторичных сопутствующих состояний при ожирении [36].

\section{СПИСОК ЛИТЕРАТУРЫ | REFERENCES}

1. Adams ST, Salhab M, Hussain Zl, et al. Obesity-related hypertension and its remission following gastric bypass surgery - A review of the mechanisms and predictive factors. Blood Press. 2012;22(3):131-137. doi: 10.3109/08037051.2012.749570.

2. Andersen RE. The spread of the childhood obesity epidemic. CMAJ 2000;163(11):1461-1462. PMC80413.

3. 3- Douard V, Ferraris RP. Regulation of the fructose transporter GLUT5 in health and disease. American Journal of Physio/ogy-Endocrinology and Metabolism. 2008;295(2):E227-E237. doi: 10.1152/ajpendo.90245.2008.

4. Heinz F, Lamprecht W, Kirsch J. Enzymes of fructose metabolism in human liver. J. Clin. Invest. 1968;47(8):1826-1832. doi: 10.1172/jci105872.

5. Mayes PA. Intermediary metabolism of fructose. The American Journal of Clinical Nutrition. 1993;58(5):754S-765S. doi: 10.1093/ajcn/58.5.754S

6. Parks EJ, Skokan LE, Timlin MT, Dingfelder CS. Dietary Sugars Stimulate Fatty Acid Synthesis in Adults. The Journal of Nutrition. 2008;138(6):1039-1046. doi: 10.1093/jn/138.6.1039

7. Basciano H, Federico L, Adeli K. Fructose, insulin resistance and metabolic dyslipidemia Nutr. Metab. 2005;2(1):5. doi: 10.1186/1743-7075-2-5.

8. Lê K-A, Tappy L. Metabolic effects of fructose. Curr. Opin Clin. Nutr. Metab. Care. 2006;9(4):469-475. doi: 10.1097/01. mco.0000232910.61612.4d.

9. Havel PJ. Dietary fructose: implications for dysregulation of energy homeostasis and lipid/carbohydrate metabolism. Nutr. Rev. 2005;63(5):133-157.

10. Brasaemle DL. Thematic review series: Adipocyte Biology. The perilipin family of structural lipid droplet proteins: stabilization of lipid droplets and control of lipolysis. J. Lipid Res. 2007;48(12):2547-2559. doi: 10.1194/jlr.R700014-JLR200.
11. Foretz M, Carling D, Guichard C, et al. AMP-activated Protein Kinase Inhibits the Glucose-activated Expression of Fatty Acid Synthase Gene in Rat Hepatocytes. J. Biol. Chem. 1998;273(24):14767-14771. doi: 10.1074/jbc.273.24.14767.

12. Foretz $M$, Ancellin $N$, Andreelli $F$, et al. Short-Term Overexpression of a Constitutively Active Form of AMP-Activated Protein Kinase in the Liver Leads to Mild Hypoglycemia and Fatty Liver. Diabetes. 2005:54(5):1331-1339. doi: 10.2337/diabetes.54.5.1331.

13. Denu JM. Linking chromatin function with metabolic networks: Sir2 family of NAD+-dependent deacetylases. Trends Biochem. Sci. 2003;28(1):41-48. doi: 10.1016/s0968-0004(02)00005-1.

14. Lafontan M. Advances in adipose tissue metabolism. Int. J. Obes. 2009;32(S7):S39-S51. doi: 10.1038/ijo.2008.237.

15. Davies BSJ, Beigneux AP, Barnes RH, et al. GPIHBP1 Is Responsible for the Entry of Lipoprotein Lipase into Capillaries. Cell Metab. 2010;12(1):42-52. doi: 10.1016/j.cmet.2010.04.016.

16. Votruba SB, Jensen MD. Regional Fat Deposition as a Factor in FFA Metabolism. Annu. Rev. Nutr. 2007;27(1):149-163. doi: 10.1146/annurev.nutr.27.061406.093754.

17. Lafontan M, Langin D. Lipolysis and lipid mobilization in human adipose tissue. Prog. Lipid Res. 2009;48(5):275-297. doi: 10.1016/j. plipres.2009.05.001.

18. Lafontan M, Moro C, Berlan M, et al. Control of lipolysis by natriuretic peptides and cyclic GMP. Trends Endocrinol. Metab. 2008;19(4):130-137. doi: 10.1016/j.tem.2007.11.006.

19. Stich V, De Glisezinski I, Crampes F, et al. Activation of a2-adrenergic receptors impairs exercise-induced lipolysis in SCAT of obese subjects. American Journal of Physiology-Regulatory, Integrative and Comparative Physiology. 2000;279(2):R499-R504. doi: 10.1152/ajpregu.2000.279.2.R499

20. Ahima RS, Flier JS. Adipose tissue as an endocrine organ. Trends Endocrinol. Metab. 2000;11(8):327-332. 
21. Trayhurn P, Wood IS. Adipokines: inflammation and the pleiotropic role of white adipose tissue. Br. J. Nutr. 2007;92(03):347. doi: 10.1079/bjn20041213

22. ClÉMent K, Viguerie N, Poitou C, et al. Weight loss regulates inflammation-related genes in white adipose tissue of obese subjects. The FASEB Journal. 2004;18(14):1657-1669. doi: 10.1096/fj.04-2204com.

23. Weisberg SP, McCann D, Desai M, et al. Obesity is associated with macrophage accumulation in adipose tissue. J. Clin. Invest. 2003;112(12):1796-1808. doi: 10.1172/jci200319246.

24. Xu H, Barnes GT, Yang Q, et al. Chronic inflammation in fat plays a crucial role in the development of obesity-related insulin resistance. J. Clin. Invest. 2003;112(12):1821-1830. doi: 10.1172/jci200319451.

25. Sierra-Honigmann MR, Nath AK, Murakami C, et al. Biological action of leptin as an angiogenic factor. Science. 1998;281(5383):1683-1686.

26. Imparl-Radosevich J, Deas S, Polansky MM, et al. Regulation of PTP-1 and Insulin Receptor Kinase by Fractions from Cinnamon: Implications for Cinnamon Regulation of Insulin Signalling. Horm. Res. Paediatr. 1998:50(3):177-182. doi: 10.1159/000023270.

27. Bandyopadhyay GK, Yu JG, Ofrecio J, Olefsky JM. Increased p85/55/50 Expression and Decreased Phosphotidylinositol 3-Kinase Activity in Insulin-Resistant Human Skeletal Muscle. Diabetes. 2005:54(8):2351-2359. doi: 10.2337/diabetes.54.8.2351

28. Hotamisligil G kS, Peraldi P, Budavari A, et al. IRS-1-Mediated Inhibition of Insulin Receptor Tyrosine Kinase Activity in TNF-alpha- and Obesity-Induced Insulin Resistance. Science. 1996;271(5249):665-670 doi: 10.1126/science.271.5249.665.

29. Messerli FH. Cardiovascular effects of obesity and hypertension. Lancet. 1982;1(8282):1165-1168.

30. Grundy SM. Atherogenic dyslipidemia associated with metabolic syndrome and insulin resistance. Clin. Cornerstone. 2006:8 Suppl 1:S21-27.

31. Reaven GM. THE INSULIN RESISTANCE SYNDROME: Definition and Dietary Approaches to Treatment. Annu. Rev. Nutr. 2005;25(1):391-406. doi: 10.1146/annurev.nutr.24.012003.132155.

32. Hardie DG. AMPK and Raptor: Matching Cell Growth to Energy Supply. Mol. Cell. 2008;30(3):263-265. doi: 10.1016/j.molcel.2008.04.012.

33. Halliwell B. Oxidative stress and neurodegeneration where are we now? J. Neurochem. 2006;97(6):1634-1658. doi: 10.1111/j.1471-4159.2006.03907.x.

34. Balaban RS, Nemoto S, Finkel T. Mitochondria, Oxidants, and Aging Cell. 2005;120(4):483-495. doi: 10.1016/j.cell.2005.02.001

35. Lotharius J, Brundin P. Pathogenesis of parkinson's disease: dopamine, vesicles and a-synuclein. Nature Reviews Neuroscience. 2002;3(12):932-942. doi: 10.1038/nrn983.

36. Maes M, Song C, Lin A, et al. The effects of psychological stress on humans: increased production of pro-inflammatory cytokines and a Th1-like response in stress-induced anxiety. Cytokine. 1998;10(4):313-318

37. Raison CL, Demetrashvili M, Capuron L, Miller AH. Neuropsychiatric adverse effects of interferon-alpha: recognition and management. CNS Drugs. 2005:19(2):105-123. PMC1255968.

38. Jessop DS, Dallman MF, Fleming D, Lightman SL. Resistance to Glucocorticoid Feedback in Obesity. J. Clin. Endocr. Metab. 2001;86(9):4109-4114. doi: 10.1210/jcem.86.9.7826.

39. Anacker C, Zunszain PA, Carvalho LA, Pariante CM. The glucocorticoid receptor: Pivot of depression and of antidepressant treatment?
Psychoneuroendocrinology. 2011:36(3):415-425. doi: 10.1016/j. psyneuen.2010.03.007

40. Raison CL, Capuron L, Miller AH. Cytokines sing the blues: inflammation and the pathogenesis of depression. Trends Immunol. 2006:27(1):24-31. doi: 10.1016/j.it.2005.11.006.

41. Pittenger C, Duman RS. Stress, Depression and Neuroplasticity: A Convergence of Mechanisms. Neuropsychopharmacology. 2007;33(1):88-109. doi: 10.1038/sj.npp.1301574.

42. Maes M, Schotte C, Scharpé S, et al. The effects of glucocorticoids on the availability of L-tryptophan and tyrosine in the plasma of depressed patients. J. Affect. Disord. 1990;18(2):121-127. doi: 10.1016/0165-0327(90)90068-j.

43. Markus CR, Olivier B, Panhuysen GEM, et al. The bovine protein a-lactalbumin increases the plasma ratio of tryptophan to the other large neutral amino acids, and in vulnerable subjects raises brain serotonin activity, reduces cortisol concentration, and improves mood under stress. The American Journal of Clinical Nutrition. 2000;71(6):1536-1544. doi: 10.1093/ajen/71.6.1536.

44. Roy EJ, Takikawa O, Kranz DM, et al. Neuronal localization of indoleamine 2,3-dioxygenase in mice. Neurosci. Lett. 2005;387(2):95-99. doi: 10.1016/j.neulet.2005.07.010.

45. Guillemin GJ, Smythe G, Takikawa O, Brew BJ. Expression of indoleamine 2,3-dioxygenase and production of quinolinic acid by human microglia, astrocytes, and neurons. Glia. 2005;49(1):15-23. doi: 10.1002/glia.20090.

46. Frenois F, Moreau M, O'Connor J, et al. Lipopolysaccharide induces delayed FosB/DeltaFosB immunostaining within the mouse extended amygdala, hippocampus and hypothalamus, that parallel the expression of depressive-like behavior. Psychoneuroendocrinology. 2007:32(5):516-531. doi: 10.1016/j.psyneuen.2007.03.005.

47. Stone TW, Darlington LG. Endogenous kynurenines as targets for drug discovery and development. Nature Reviews Drug Discovery. 2002;1 (8):609-620. doi: 10.1038/nrd870.

48. Moyer BJ, Rojas IY, Kerley-Hamilton JS, et al. Inhibition of the aryl hydrocarbon receptor prevents Western diet-induced obesity. Model for AHR activation by kynurenine via oxidized-LDL, TLR2/4, TGFß, and IDO1. Toxicol. Appl. Pharmacol. 2016;300:13-24. doi: 10.1016/j.taap.2016.03.011

49. Yu E, Ruiz-Canela M, Guasch-Ferré $M$, et al. Increases in Plasma Tryptophan Are Inversely Associated with Incident Cardiovascular Disease in the Prevención con Dieta Mediterránea (PREDIMED) Study. The Journal of Nutrition. 2017:jn241711. doi: 10.3945/jn.116.241711.

50. Mudry JM, Alm PS, Erhardt S, et al. Direct effects of exercise on kynurenine metabolism in people with normal glucose tolerance or type 2 diabetes. Diabetes Metab. Res. Rev. 2016;32(7):754-761. doi: 10.1002/dmrr.2798.

51. Weisberg SP, McCann D, Desai M, et al. Obesity is associated with macrophage accumulation in adipose tissue. J. Clin. Invest. 2003;112(12):1796-1808. doi: 10.1172/jci200319246.

52. Eom T-Y, Jope RS. Blocked Inhibitory Serine-Phosphorylation of Glycogen Synthase Kinase-3a/ $\beta$ Impairs In Vivo Neural Precursor Cell Proliferation. Biol. Psychiatry. 2009;66(5):494-502. doi: 10.1016/j.biopsych.2009.04.015.

53. Kopelman PG. Obesity as a medical problem. Nature. 2000;404(6778):635-643. doi: 10.1038/35007508.

\section{ИНФОРМАЦИЯ ОБ АВТОРАХ [AUTHORS INFO]}

*Yassine Chahirou; адрес: пр-т de L'Université, Кенитра, Марокко [address: Av. de L'Université, Kénitra, Morocco]; ORCID: https://orcid.org/0000-0002-0755-8811; e-mail: yassine_chahirou@hotmail.fr

Abdelhalim Mesfioui; ORCID: https://orcid.org/0000-0002-1028-7469; e-mail: a.mesfioui@yahoo.fr

Ali Ouichou; ORCID: https://orcid.org/0000-0001-9704-8526; e-mail: ouichou@hotmail.com

Aboubaker Hessni; ORCID: https://orcid.org/0000-0003-4890-7069; e-mail: elhessni70@yahoo.fr

ЦИТИРОВАТЬ:

Chahirou Y., Mesfioui A., Ouichou A., Hessni А. Адипокины: механизмы метаболических и поведенческих расстройств // Ожирение и метаболизм. - 2018. - Т.15. — №. 3 - С. 14-20. doi: 10.14341/OMET9430

\section{TO CITE THIS ARTICLE:}

Chahirou Y, Mesfioui A, Ouichou A, Hessni A. Adipokines: mechanisms of metabolic and behavioral disorders. Obesity and metabolism. 2018;15(3):14-20. doi: 10.14341/OMET9430 